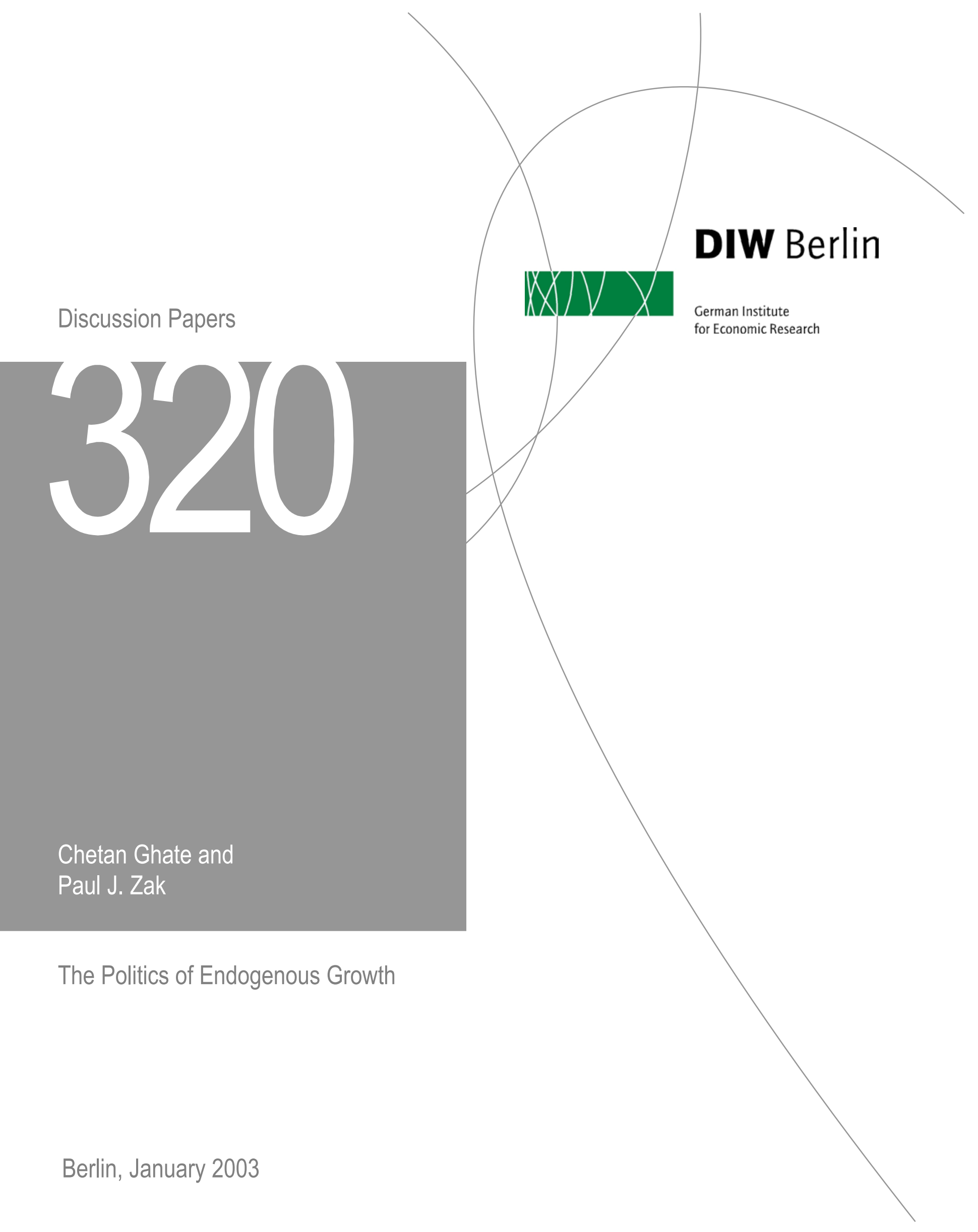


Opinions expressed in this paper are those of the author and do not necessarily reflect views of the Institute.

\section{DIW Berlin}

\section{German Institute}

for Economic Research

Königin-Luise-Str. 5

14195 Berlin,

Germany

Phone +49-30-897 89-0

Fax +49-30-897 89-200

www.diw.de

ISSN 1619-4535 


\title{
The Politics of Endogenous GROWTH $^{*}$
}

\author{
Chetan Ghate \\ Indian Statistical Institute, Delhi, and DIW, Berlin \\ AND \\ PAUL J. ZAK \\ Claremont Graduate University
}

JANUARY 13, 2003

${ }^{*}$ We thank Arthur Denzau and Thomas Borcherding for useful comments which have improved this paper. This paper was completed while Chetan Ghate was visiting the Macro Analysis and Forecasting department at DIW Berlin. The usual disclaimer applies. Correspondence to: Chetan Ghate, Visiting Fellow, Department of Macro Analysis and Forecasting, DIW, Knigin-Luise-Strasse 5, 14195 Berlin (Steglitz), Germany. E-mail: cghate@diw.de \& cghate@coloradocollege.edu. Tel: 049-030-89 789529. 


\begin{abstract}
Is it politically feasible for governments to engineer endogenous growth? This paper illustrates two reasonable political decision mechanisms by which fiscal policy generates endogenous growth with a single accumulable factor, under a constant returns to scale production technology, and without production externalities. In the first mechanism, optimal policies are chosen by the government to maximize constituent support by raising aggregate income. In the second mechanism, optimal policies are determined in a voting equilibrium where agents are concerned only with their own incomes. We demonstrate that policies that target aggregates generate balanced growth and are Pareto optimal. Policies chosen by the median voter also produce balanced growth, but result in public investment $50 \%$ below the socially optimal level.
\end{abstract}

Keywords: Public Investment, Positive Political Economy, Median Voter Theorem, Endogenous Growth, Journal of Economic Literature Classification Number: P16: Political Economy of Capitalism; E62: Fiscal Policy; O40 Economic Growth. 


\section{INTRODUCTION}

Public investment is recognized as a constituent of economic growth (Aschauer, 1989; Stinespring, 2002). Public investment is important from a development viewpoint because it is a choice variable for the government. Recent empirical studies quantify the impact of public investment on growth. For instance, in a large sample of countries the World Bank (1994) reports that a 1\% increase in the stock of infrastructure leads to a $1 \%$ increase in GDP. Hirschman (1958) identified public investment as attracting private investment, thereby serving as a viable development strategy, a notion formalized by Barro (1990). Rioja (1999) estimates an elasticity of public investment on growth of 2.5 when the "crowding in of private investment is taken into account. ${ }^{1}$ While these works identify the effect of public investment on growth, they ignore the political process that determines the level of public investment.

Because politicians determine government expenditures, fiscal flows reflect their objectives (Mueller, 1989; Ghate \& Zak, 2002). Indeed, politicians maintain constituent support by raising incomes through enacted policies. Lewis-Beck (1990) reports that voters consistently reveal that economic health is among the most important factors affecting their choices in elections. Substantial empirical evidence indicates that politicians set policy (and claim credit for policies) presuming that voters care about aggregate economic outcomes (Fiorina, 1981; Tufte, 1978). ${ }^{2}$

This paper characterizes how political systems determine the choice of public investment, as in Persson \& Tabellini (2000 ch. 12), and then analyzes the associated growth trajectories for each policy set. We do this to address a fundamental issue in the political economy of economic development: if policy is chosen by self-interested politicians, can endogenous growth obtain? We cast the analysis in a framework which is unlikely to produce endogenous growth a constant returns to scale production

\footnotetext{
${ }^{1}$ Also see the recent work by Shioji (2001), Turnovsky \& Fisher (1998), Glomm \& Ravikumar (1994, 1997), and the survey by Easterly \& Levine (2001).

${ }^{2}$ Bueno de Mesquita et al (2002) identify institutional arrangements that lead politicians to enact poor economic policies in order to stay in power. This occurs when an autocrat or small cabal rules a country, a case we do not consider; for a related model with varying institutional arrangements see Feng, Kugler \& Zak (2002).
} 
function without production externalities and a single accumulable factor in order to ascertain the fiscal politics that are mostly likely to produce sustained growth.

Two political mechanisms are shown to induce endogenous growth. The first is when constituent support rises directly with the growth in aggregates so that policymakers set policy with income growth explicitly as the goal; the second is when voters choose among a set of politicians based on their policy stances taking only their individual incomes into account. The models in this paper also demonstrate how a period-to-period strategic policy-setting problem is embedded into a dynamic general equilibrium framework by presenting a "modified planning problem in which only the economys aggregate state, not agents utility functions, are needed to set policy.

Performing a welfare analysis, we demonstrate that the economys growth trajectory when aggregate income is politicians goal is Pareto efficient, while the voting equilibrium results in an under-provision of public investment. We also show that the shortfall in public investment in the voting equilibrium is proportional to the difference between the median voter's and average voter's assets. As a result, public investment is substantially lower when voters determine policy individually compared to when politicians set policy by focusing on aggregates. Our primary finding is that while both mechanisms generate perpetual growth, only when politicians choose public investment directly to maximize growth are policies efficient.

\section{Aggregate Policy Setting and Endogenous Growth}

Since growth increases tax revenues and promotes political stability (Zak, 2000; \& Ghate, Le and Zak, 2002), in this section we model a representative policy-maker as maximizing capital deepening by choosing an income tax rate at time $t, \tau_{t} \geq 0$, and public investment, $\lambda_{t} \geq 0 .{ }^{3}$ This construct obviates the need for policy-setters to know consumers' utility functions; rather they need only observe the economy's state

\footnotetext{
${ }^{3}$ This "modified planning problem, was introduced in Feng, Kugler \& Zak (1999).
} 
variable, private capital stock $K_{t}$, when making policy choices at time $t .{ }^{4}$ Increases in public investment raise private productivity but come at the cost of higher taxes, so its growth effect is ambiguous.

Because we seek to generate balanced growth paths, we derive optimal fiscal policy using a Cobb-Douglas production function, $Y_{t}=K_{t}^{\alpha} \lambda_{t}^{1-\alpha}$, for $\alpha \in(0,1)$. Population is constant and normalized to unity, and leisure is not valued. The form of the production function indicates that public investment (e.g. education expenditures) is necessary to produce output.

In this model, politicians solve an optimal fiscal policy problem each period to maintain the support of constituents and therefore the likelihood of remaining in power by maximizing the growth of productive capacity. ${ }^{5}$ Politicians decision calculus at time $t$ is

$$
\operatorname{Max}_{\lambda, \tau} \frac{K_{t+1}}{K_{t}}
$$

s.t.

$$
\begin{aligned}
K_{t+1} & =s\left[Y_{t}-\tau_{t}\right]+(1-\delta) K_{t} \\
\tau_{t} & =\lambda_{t} .
\end{aligned}
$$

where $C$ is aggregate consumption, $\delta \in[0,1]$ is the depreciation rate for capital, and $s \in(0,1)$ is the savings rate. Equation (2) shows that in equilibrium, net investment $\left(K_{t+1}(1-\delta) K_{t}\right)$ equals savings from after-tax income. Equation (3) is the government budget constraint which equates tax revenue to public investment. For simplicity, government borrowing is disallowed. It is important to reiterate that we model public investment as a non-accumulable factor since if two types of capital accumulate, it is well-established that endogenous growth obtains (Aghion \& Howitt, 1998).

\footnotetext{
${ }^{4}$ This is equivalent to maximizing consumers indirect utility functions which are parameterized by the fiscal policy variables. Here we assume consumers are Solovian which substantially simplifies the analysis. The proportional savings assumption has solid empirical support (Campbell \& Mankiw, 1991; Blinder and Deaton, 1985).

${ }^{5}$ Maximization of the growth in the capital stock, or output growth are identical on a balanced growth path; with the former calculations simpler.
} 
The solution to the optimal fiscal policy problem (1) to (3) is given by

$$
\lambda_{t}^{\star}=(1-\alpha)^{\frac{1}{\alpha}} K_{t}=\tau^{\star}
$$

Importantly, optimal public investment, (4), is linearly related to private capital. The following proposition shows that the policy set $\left\{\lambda^{\star}, \tau^{\star}\right\}_{t=0}^{\infty}$ is Pareto optimal in a representative agent economy.

Proposition 1 Suppose that all agents in the economy are identical and infinitely lived. Then the growth maximizing policy (4) for some initial condition $K_{0}>0$, is Pareto optimal.

Proof. The Pareto optimal fiscal policy problem is the solution to

$$
\operatorname{Max}_{\tau, \lambda} \sum_{t=0}^{\infty} \beta^{t} U\left(C_{t}\right)
$$

s.t

$$
\begin{aligned}
K_{t+1} & =s\left[F\left(K_{t}, \lambda_{t}\right) \tau_{t}\right]+(1-\delta) K_{t} \\
\lambda_{t} & =\tau_{t}
\end{aligned}
$$

where $U(C)$ is a smooth representation of preferences with the usual properties. Using the Cobb-Douglas production function given above, the solution to the Pareto problem can be shown to match growth maximization problem as claimed.

Next, we characterize the aggregate dynamics induced by this fiscal policy. Substituting (4) into the capital market equilibrium condition (2), the evolution of the economy is given by

$$
K_{t+1}=\left[s \alpha(1-\alpha)^{\frac{1-\alpha}{\alpha}}+1-\delta\right] K_{t}
$$

The first term in (9) captures the complementarity of private capital and public investment in producing output, resulting in a term that is linear in $K_{t}$. That is, optimal fiscal policy using a constant returns to scale production function results in a linear mapping from capital to output due to production complementarities. 
The economy with optimal fiscal policy, (9), grows without bound if

$$
s \geq \frac{\delta(1-\alpha)^{\frac{\alpha-1}{\alpha}}}{\alpha} .
$$

If inequality (10) is satisfied, optimal fiscal policy produces an AK model - for any $K_{0}>0$, the economy exhibits balanced growth endogenously. ${ }^{6}$

The model in this section illustrates that when politicians choose taxes and public investment to explicitly maximize growth, the resulting equilibrium trajectory is Pareto optimal and generates perpetual balanced growth as long as savings is not too low. This result provides a rationale for the government to choose the level of public investment wisely. If taxes are too high due to other expenditure items endogenous growth will not obtain (Ghate \& Zak, 2002), nor will growth arise if public investment is too low.

\section{Voting for Policy}

The foregoing result reveals that public investment can support sustained growth. Yet, the decision calculus, while appropriate for a highly unified government (e.g. a market-oriented dictatorship or a parliamentary system with a strong majority), it does not fit the decision-making process in a competitive democracy. In this section we extend the analysis above by investigating the dynamics of an economy with a continuum of heterogeneous agents who vote over the fiscal policies proposed by a continuum of politicians. The politician who receives the most votes implements the fiscal policy she has proposed.

In this model, agents are identified by their wealth, where a type $i$ agent has assets $a^{i}$ and agents have unit mass. ${ }^{7}$ The index $i \in(0, \infty)$ orders agents so that $i_{2}>i_{1}$ implies $a^{i_{2}}>a^{i_{1}}$. In order to compare this model to the one derived above, we assume that agents save a uniform and fixed proportion $s \in(0,1)$ of their labor income each period, and limit all investments to last a single period. Consumers vote for fiscal policies to maximize discounted lifetime utility. Since voting occurs over a

\footnotetext{
${ }^{6}$ If condition (10) is not satisfied, the economy contracts to the origin.

${ }^{7}$ For simplicity, we abstract from heterogeneity in wages.
} 
single issue (after substituting out $\tau$ using the government budget constraint) and preferences are single peaked, the median voter theorem applies. After agents have made their consumption/saving choices that are parameterized by fiscal policies, the choice of a politician (equivalently, a fiscal policy) for a type $i$ agent at time $t$ is

$$
\operatorname{Max}_{\tau, \lambda} \Sigma_{t=0}^{\infty} \beta^{t} U\left(c_{t}^{i}\right)
$$

s.t.

$$
\begin{aligned}
c_{t}^{i} & =w_{t}-\tau_{t}+R_{t} a_{t}^{i}-a_{t+1}^{i} \\
a_{t+1}^{i} & =s\left[w_{t}-\tau_{t}+R_{t} a_{t}^{i}\right] \\
\tau_{t} & =\lambda_{t}
\end{aligned}
$$

Equation (12) is the agent's budget constraint equating time period $t$ consumption to after-tax wage and interest income minus assets held for the following period, $a_{t+1}^{i}$, with the assumption of proportional savings given by equation (13). The term $R \equiv r+1-\delta$ is the yield on savings, with $r$ the interest rate. The last equation, (14), is the government budget constraint equating tax revenue to public investment.

Agents understand that factor prices depend on public investment when choosing fiscal policy, even though factor markets are, by assumption, perfect competitive. Profit maximization by competitive firms, taking public investment $\lambda$ as given, leads to factor prices,

$$
\begin{aligned}
r_{t} & =\alpha K_{t}^{\alpha-1}\left(\lambda_{t}\right)^{1-\alpha} \\
w_{t} & =(1-\alpha) K_{t}^{\alpha}\left(\lambda_{t}\right)^{1-\alpha}
\end{aligned}
$$

Using (15) and (16), the unique solution to the voting problem (11) to (14), determined by the median voter, is

$$
\lambda_{t}^{m}=(1-\alpha)^{\frac{1}{\alpha}} K_{t}\left[1-\alpha+\alpha a_{t}^{m} K_{t}^{-1}\right]^{\frac{1}{\alpha}},
$$

where $a^{m}$ are the assets of the median voter. Equation (17) shows that the preferred level of public investment is increasing in the assets of the median voter. This obtains as $\lambda$ increases wages and the return to savings, which, in turn, increases after-tax 
income. Similarly, public investment rises with the private capital stock. Further, as $a_{t}^{m} \rightarrow K_{t}, \lambda_{t}^{m}$ converges to the first best policy $\lambda_{t}^{\star}$ given by (4). Hence, as the median voter converges to become the average voter, the level of public of investment preferred by the median voter converges to the first best. Lastly, note that the level of under-provision of public investment in a voting equilibrium is proportional to the difference between the median voter's and average voters assets. ${ }^{8}$

Before the aggregate dynamics induced by this fiscal policy can be determined, the relationship between the median voter's wealth and aggregate wealth must be specified since public investment (17) depends on the median voter's wealth. Because individual assets sum to aggregate capital $\int_{0}^{\infty} a_{t}^{i} d \mu=K_{t}$, where $\mu$ is an appropriately defined probability measure over agents, each individual owns some proportion of the capital stock. Define the proportion of the aggregate capital stock owned by the median voter as $a_{t}^{m}=\phi K_{t}$, for some $\phi \in(0,1)$. That $\phi$ is constant over time is consistent with constraint (13) in which agents save a fixed proportion of income, and indicates that the distribution of wealth does not change over time.

With a time-invariant distribution of wealth, optimal public investment is

$$
\lambda_{t}^{m}=(1-\alpha)^{\frac{1}{\alpha}}\left[(1-\alpha(1-\phi)]^{\frac{1}{\alpha}} K_{t},\right.
$$

which is strictly positive under the maintained parameter restrictions.

The aggregate dynamics of this economy are described by the capital market clearing condition

$$
K_{t+1}=s \int_{0}^{\infty}\left[w_{t}-\tau+R_{t} a_{t}^{i}\right] d \mu .
$$

Using the adding up condition that relates individual assets to the capital stock, (19) can be written as,

$$
K_{t+1}=s\left[w_{t}-\tau+R_{t} K_{t}\right] .
$$

Embedding factor prices (15), (16), and the optimal policy choice (18) into the capital market clearing condition (20), produces the dynamic equation

$$
K_{t+1}=A K_{t},
$$

\footnotetext{
${ }^{8}$ One implication of (13) is that the model produces a non-degenerate stationary asset distribution if $s R=1$. When $s R>1$, wealth inequality diverges. If $s R<1$, all households converge to the same wealth level and the median household chooses the first best level of public investment.
} 
where $A=s\left[(1-\alpha)^{\frac{1}{\alpha}}(1-\alpha(1-\phi))^{\frac{1}{\alpha}}+\alpha(1-\alpha)^{\frac{1-\alpha}{\alpha}}(1-\alpha(1-\phi))^{\frac{1-\alpha}{\alpha}}+1-\delta\right]>0$. Thus, voting over fiscal policies again produces an AK model. It is straightforward to prove that the level of public investment chosen by voters is below the Pareto optimal level as the median consumer does not take into account aggregate growth when choosing policy. The extent of this distortion appears to be quite large, with the proportional difference between the two policies being $[1-\alpha(1-\phi)]^{\frac{1}{\alpha}}$. For instance, in a large economy such as the U.S, the proportion of aggregate wealth held by the median voter, $\phi$, is near zero, while $\alpha$ is typically measured around $\frac{1}{3}$ (Cooley, 1995, Ch. 1). This puts the public investment chosen by the median voter $54 \%$ below the Pareto optimal level.

\section{Conclusion}

We have demonstrated two simple mechanisms where the politics of choosing fiscal policies transform otherwise standard growth models with constant returns to scale production into endogenous growth models, without appealing to externalities. Notably, the models herein produce balanced growth paths, qualitatively matching growth in developed countries, and do so using politically reasonable optimal policy selection techniques. As a result, we have shown that balanced growth obtains without the knife-edge parameter restrictions required by many endogenous growth models. Our primary result is that when voters care about the aggregate state of the economy, politicians set policy with this in mind resulting in first-best (Pareto optimal) outcomes. In contrast, when there is a continuum of policies to choose from and agents vote directly the policy that they individually prefer, endogenous growth still obtains, but public investment is only half the Pareto optimal level resulting in a substantial welfare loss. 


\section{REFERENCES}

Aghion, Phillip And Howitt, Peter, 1998, Endogenous Growth Theory, MIT Press.

Aschauer, David A., 1989, Is Public Expenditure Productive? Journal of Monetary Economics, 23:177-200.

Barro, Robert J., 1990, Government Spending in a Simple Model of Endogenous Growth, Journal of Political Economy, 98:103-25.

Blinder, Allen And Deaton, Angus, 1985, The Time-Series Consumption Function Revisited, in Brookings Papers in Economic Activity 2, William C. Brainard and George L. Perry, eds., The Brookings Institution.

Bueno de Mesquita, Bruce, Siverson, Randy, Smith, Alastair, And MorRow, JAMEs, 2002, The Logic of Political Survival, manuscript, Stanford University.

Campbell, John Y., And Mankiw, N. Gregory, 1991, The Response of Consumption to Income: A Cross-Country Investigation, European Economic Review, $35(4): 723-56$.

Cooley, Thomas F., ed., 1995, Frontiers of Business Cycle Research, Princeton University Press.

Feng, Yi, Kugler, Jacek, And Zak, Paul J., 2002, The Politics of Economic Growth, American Journal of Political Science, forthcoming.

Easterly, William, And Levine, Ross, 2001, It's not Factor Accumulation: Stylized Facts and Growth Models, World Bank Economic Review, Vol 15(2), 177-219.

Easterly, William, and Rebelo, Sergio, 1993, Fiscal Policy and Economic Growth: An Empirical Investigation, Journal of Monetary Economics, 32: 417458.

Fiorina, Morris, P., 1981, Retrospective Voting in American National Elections, Yale University Press.

Ghate, Chetan, 2001, Lobbying, The Composition of Government Expenditures, and the Politics of Fiscal Policy, Australian Economic Papers, 40(2): 133-145.

Ghate, Chetan, And Zak, Paul J., 2002, Growth of Government and the Politics 
of Fiscal Policy, Structural Change and Economic Dynamics, 13(4): 435-455.

Ghate, Chetan, Le, Q., And Zak, Paul.J., 2002, Optimal Fiscal Policy in an Economy Facing Socio Political Instability, Forthcoming, Review of Development Economics.

Glomm, Gerhard, and B. Ravikumar, 1997, Productive Government Expenditures and Long-Run Growth, Journal of Economic Dynamics and Control, 21, 183-204.

Glomm, Gerhard, And B. Ravikumar, 1994, Public Investment in Infrastructure in a Simple Growth Model, Journal of Economic Dynamics and Control, 18, 11731187.

Hirschman, A., 1958, The Strategy of Economic Development, Yale University Press, New Haven and London.

Lewis-Beck, Michael S., 1990, Economics and Elections: The Major Western Democracies, University of Michigan Press.

Mueller, Dennis, 1989, Public Choice, $2^{\text {nd }}$ Edition, Cambridge University Press.

Persson, Torsten, and Tabellini, Guido, 2000, Mit Press.

Rebelo, Sergio, 1991, Long Run Policy Analysis and Long Run Growth, Journal of Political Economy, 99(3): 501-521.

Rioja, Felix, 1999, Productiveness and Welfare Implications of Public Infrastructure: A Dynamic Two Sector General Equilibrium Analysis, Journal of Development Economics, 58 (2): 387-404.

Romer, Paul, 1986, Increasing Returns and Long Run Growth, Journal of Political Economy, 94(5):1002-1037.

Romer, Paul, 1990, Endogenous Technological Change, Journal of Political Economy, 98(5):71-102.

Solow, Robert, 1956, A Contribution to the Theory of Economic Growth, Quarterly Journal of Economics, 70(1): 65-94.

Shioji, Etsuro, 2001, Public Capital and Economic Growth: A Convergence Approach, Journal of Economic Growth, 6(3): 205-227.

Stinespring, John R., 2002, Public Capital and Optimal Finance in a Growing Economy, Doctoral Dissertation, Claremont Graduate University. 
Tufte, Edward, 1978, Political Control of the Economy, Princeton University Press.

Turnovsky, Steven J., And Fisher, W.H., 1998, Public Investment, Congestion, and Private Capital Accumulation, The Economic Journal, 108:399-413.

World BANK, 1994, World Development Report.

ZAK, PAUL, 2000, Socio-Political Instability and the Problem of Development, Chapter 4 in Governing for Prosperity, Bruce Bueno de Mesquita and Hilton Root, Eds., Yale University Press. 